\title{
Ergonomic Recommendation of Suitable Toilet Seat Height for Older Thai People
}

Pornthip Tharbthong, M.Sc. ${ }^{1}$, Samerjit Homrossukon, Ph.D. ${ }^{1}$, Pagamas Piriyaprasarth, Ph.D. ${ }^{2}$

${ }^{1}$ Medical Engineering, Faculty of Engineering, Thammasat University, Klong Luang, Pathum Thani 12120, Thailand.

${ }^{2}$ Faculty of Physical Therapy, Mahidol University, Salaya, Nakhon Pathom 73170, Thailand.

Received 1 July 2019 • Revised 17 October 2019 • Accepted 18 October 2019 • Published online 26 November 2019

\section{Abstract:}

Objective: This study aimed to determine the main factors affecting older people as they rise from a toilet seat and to identify the suitable toilet seat height for this population.

Material and Methods: Data from 342 older people both male and female aged 60 years and older were used to design a mock-up toilet with a specified seat width according to the $95^{\text {th }}$ percentile of hip breadth. The data of lower leg length were used to design toilet seat height levels in the second phase in another 30 older participants at $100.0 \%$, $110.0 \%$ and $120.0 \%$ of an individual's lower leg length (LLL). Rectus femoris and gluteus maximus muscle activity, time taken while rising, pressure under the thighs and satisfaction of the older participants were compared across three toilet seat height levels; using the repeated analysis measurements of variance. These three potential factors were then analyzed together with the prioritized factor indicated by the specialists using the Analytic Hierarchy Process.

Results: Rectus femoris muscle activity, time taken while rising, and satisfaction of the older participants in rising from toilet seat heights 100.0, 110.0 and 120.0\% LLL were significantly different ( $p$-value<0.05).

Conclusion: It was found that the suitable toilet seat height level for older people for industrial ergonomic purposes was at $110.0 \%$ LLL, which was also equivalent to the $95^{\text {th }}$ percentile of male and female LLL.

Keywords: ergonomics, older people, satisfaction, toilet seat height

Contact: Pornthip Tharbthong, M.Sc.

Medical Engineering, Faculty of Engineering, Thammasat University,

Klong Luang, Pathum Thani 12120, Thailand.

E-mail: pornthipt311@gmail.com

This is an open access article under the CC BY-NC-ND license

(http://www.jhsmr.org/index.php/jhsmr/about/editorialPolicies\#openAccessPolicy). 


\section{Introduction}

The common health problems of older people are a concern, especially physical and psychological disabilities. ${ }^{1}$ As a result of physiological declines, motor functions such as muscle weakness and balance disorders appear. Reduction of muscle usage also decreases the circulatory supply, leading to a further loss of musculature and diminution in strength. ${ }^{1}$ Particularly, weakness of lower extremity muscles could lead to difficulty in walking. In addition, balance disorders could increase the risk of falling. ${ }^{2,3}$ The decreased range of joint motion and muscle weakness could also affect sit-to-stand performance. ${ }^{4}$ These problems lead to a difficulty in rising and balancing from sitting to standing in the daily activities of older people, such as rising from a toilet ${ }^{2,3}$, which could also increase the risk of injury or falling. ${ }^{2,3,5,6}$

Another common health problem in the older adult population is constipation. ${ }^{7}$ The number of cells in the skin decreases together with collagen and elastic fiber, leading to fragile skin in this population. ${ }^{1}$ Sitting for a long time as a result of constipation or at an unsuitable seat height could therefore increase the pressure distribution under the thighs, which may lead to soft tissue injuries. ${ }^{8-13}$

Rising from a toilet involves the gluteus maximus together with the hamstrings muscles, extending the hips while the quadriceps femoris extend the knees. ${ }^{3}$ One clinical test that has been used to assess quadriceps femoris and gluteus maximus muscle performance is the Sit-to-Stand test. With a similar principle, the Five Times Sit-to-Stand test is another test that indicates lower extremity muscle strength and good balance ${ }^{14-16}$, as well as predicting falls in older people. ${ }^{15,17}$ The time taken while rising from the sitting position has also been used to indicate postural control in older people with high intrarater reliability. ${ }^{15,18}$ Most available studies explored the factors associated with rising from an office chair, such as seat height, comfort, and pressure distribution under the thighs. ${ }^{10,11,19}$ Likewise, the factors reported to affect sit-tostand performance were seat height and seat compressibility. ${ }^{20-22}$ Among existing studies, the optimal performance of the quadriceps muscles was when standing from a seat height at $100.0-120.0 \%$ of lower leg length (LLL), while 80.0 and $90.0 \%$ of LLL are unsuitable seat height levels as they lead to a difficulty in rising and balancing from sitting to standing in the daily activities of older people. ${ }^{22-24}$

As studies addressing the toilet are limited, we focused on several factors that affect the performance of rising from a chair. These included quadriceps femoris muscle performance, gluteus maximus muscle performance, pressure distribution under the thighs, time taken to sitto-stand, and comfort while sitting. ${ }^{3,14-16,25}$ In a few studies regarding toilet seat height, only performance of quadriceps femoris and gluteus maximus muscles were reported. ${ }^{3}$ Other factors that are possibly related to rising from a seating toilet in older people have not been explored.

Based on the ergonomic design principle, both the biomechanical and psychological aspects are required for consideration. Therefore, the aims of this study were to determine the factors that potentially affect rising from a toilet in older people, and to identify a suitable seat height. The five factors of interest were (1) rectus femoris muscle activity, (2) gluteus maximus muscle activity, (3) pressure distribution under the thighs, (4) time to rise, and (5) satisfaction while rising from a toilet. Three toilet seat height levels were chosen in the range of promoting optimal lower extremity muscle activity at 100.0, 110.0 and $120.0 \%$ LLL.

\section{Material and Methods}

This study consisted of two phases. The first phase aimed to measure the anthropometric data of older Thai people. These were performed in the sitting position: (1) lower leg length, (2) hip breadth, and (3) buttock to popliteal length; according to: the International Organi- 
zation for standardization of ISO 7250-1:2017, basic human body measurements for technological design. Part 1: Body measurement definitions and landmarks. ${ }^{26}$ They were recruited from communities in Ubon Ratchathani province, the largest province in Northeastern Thailand with the top five largest older Thai population. ${ }^{27}$ One previous study also concluded that the anthropometric data of largest sample could represent older population in Thailand. Furthermore, it was found that the mean of individual's LLL of this sample was in the range of $37.00-40.10 \mathrm{~cm}$ for thai people at this age. ${ }^{28}$ They were included if they were 60 years or above, able to rise from a seat without using any assistive device, and able to follow simple instructions. Sample size 342 older people were calculated from the total population of 2,373 based on sampling method of Taro Yamane being calculated from the total of population at significant level $(p-v a l u e=0.05) .^{29}$ This study was approved by the Ethics Committee of Thammasat University (COANo.198/2559). All participants signed the consent form before enrolling in this study. The samples group was categorized the measure of the anthropometric data for older people in the overall age group of 60 years and older consisting of 152 males and 190 females. The overall age group was classified in subgroups of 60-64, 65-69, 70-74 and above 75 years. The anthropometric data determined from overall group and from subgroups were approximately the same. Therefore, such data of the overall group were used to design a mock-up toilet for the next phase.

The second phase was designed with an aim to determine the factors potentially affecting rising from a toilet, and to determine a suitable toilet seat height for older people. Five potential factors affecting rising from a sitting position were extracted from the literature review: (1) rectus femoris muscle activity, (2) gluteus maximus muscle activity, (3) pressure distribution under the thighs, (4) time to rise, and (5) satisfaction while rising from a toilet. The weight attributed to these five factors was determined by six healthcare professional with ergonomic related specialists. In addition, a questionnaire for older participants in relation to the problems and satisfaction of toilet use was created by the authors. It was constructed and validated by the same specialists [content validity index $(\mathrm{CVI})=0.86]$. Area stratified random sampling from the sample in the first phase was applied in this phase.

The mock-up toilet with specified seat width was designed according to the $95^{\text {th }}$ percentile of male hip breadth. $^{10,30}$ The seat depth was chosen as the universal size in order to support the buttocks and thighs for all participants. ${ }^{31}$ Three seat height levels were selected at $100.0,110.0$ and $120.0 \%$ of individual's LLL. At these levels, the performance of quadriceps muscles was found to be optimal and the risk of injury and falls could be minimized in older people. ${ }^{12,22,24,32}$ Toilet seat height was adjusted using a firm wooden layer inserted under each participant's feet (Figure.1).

In the second phase, first, the participants were familiarized with sitting and standing from the mock-up toilet. They were then asked to sit with their back straight at each toilet seat height for five minutes. During this time, pressure distribution under the thighs was measured using a stabilizer pressure bio-feedback (Chattanooga Group, INC, USA). The instruments were secured on the top surface of the toilet seat for each trial. To measure the pressure distribution, each participant sat on the instruments for five-minutes record. This protocol was based on previous studies ${ }^{25}$ and our pilot study. Muscle activity of rectus femoris and gluteus maximus while moving from sitting to standing was recorded using the electromyography (EMG) (NORAXON, impedance $<5,000 \Omega$, bandpass 80-250 Hz). EMG signals were sampling at frequency rate of $1,000 \mathrm{~Hz}^{33}$ (Figure 1). Surface EMG preparation and data collection protocol were based on SENIAM. ${ }^{34}$ EMG data were presented as the percentage of maximum 


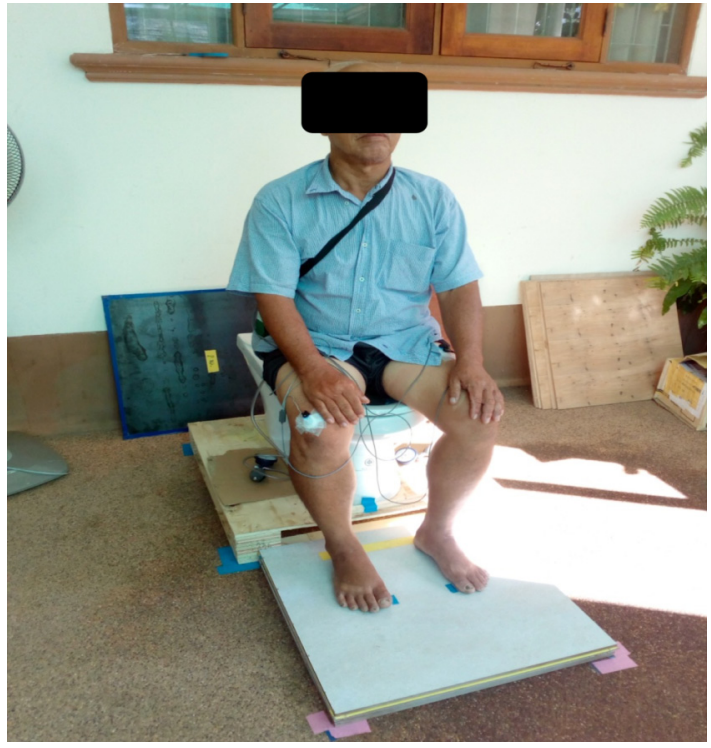

(a)

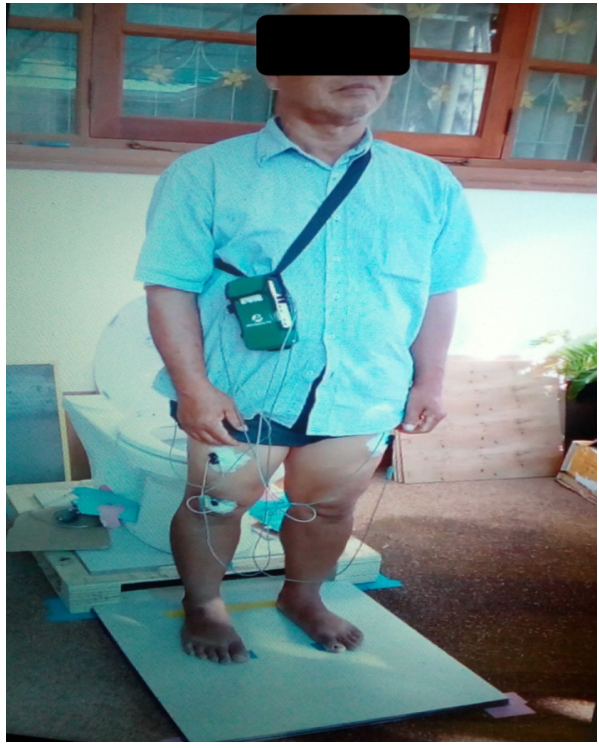

(b)

Figure 1 A participant sitting on the mock-up toilet (a) and standing (b).

voluntary contraction (\%MVC). The reliability of the surface electrode attachments and the measurement of MVC of the rectus femoris and gluteus maximus by the researchers were in acceptable agreement with the specialists.

The time taken from sitting to standing was recorded using a stopwatch for later calculation of average movement speed in rising from sitting. ${ }^{18}$ Lastly, they were asked to rate their satisfaction on toilet use using a ranking scale (3=most satisfaction, $2=$ moderate satisfaction, and 1=low satisfaction). This ranking scale and the details were created by the researchers and validated by the specialists $(C V I=1)$ (CVI $\geq 0.8=$ good content validity, $\mathrm{CVI}=1$ completed content validity). ${ }^{35}$ The order of testing among the three toilet seat height levels was random for all participants from 100.0, 110.0 and 120.0\% LLL. Each participant completed the same measurement steps as mentioned above.

Descriptive statistics were used to analyze the data in the first phase. Repeated measures ANOVA was used to determine the factors potentially affecting rising from the toilet among the three seat height levels in the second phase. With such potential factors and the different toilet seat heights by \% LLL and percentiles, the Analytic Hierarchy Process (AHP) was applied to determine a suitable toilet seat height for older people. The AHP has been implemented in the decision-making process with the priority items determined from the AHP highest score. ${ }^{36}$

\section{Results}

\section{Anthropometric data}

Results from the first phase of this study provided personal characteristics and anthropometric data of the participants in sitting. The participants were 190 females and 152 males ranging in age from 60 to 90 years, with an average height of $153.20 \mathrm{~cm}$ (S.D.=9.25) (Table 1). The data analyses showed that the $5^{\text {th }}, 50^{\text {th }}$ percentile of hip breadth were proximate for older men and women. The $95^{\text {th }}$ percentile of hip breadth was $38 \mathrm{~cm}$ for both older men and women. This was designed for extreme individuals. Therefore, the 
seat width was designed at maximum condition which is at the $95^{\text {th }}$ percentile of male hip breadth ${ }^{10,30}$ to support hip breadth for all participants (Table 2). The lower leg length of older men was $42.67 \mathrm{~cm}$ and for older women it was $40.02 \mathrm{~cm}$. The buttock to popliteal length was $46.72 \mathrm{~cm}$ and $44.75 \mathrm{~cm}$ for older men and women, respectively (Table 2)

Table 1 Characteristics of participants

\begin{tabular}{|c|c|}
\hline Characteristic & $\begin{array}{l}\text { Participants } \\
\text { Number (\%)/Mean } \pm \text { S.D. }\end{array}$ \\
\hline \multicolumn{2}{|l|}{ Sex } \\
\hline Female & $190(56.0)$ \\
\hline Male & $152(44.0)$ \\
\hline Age (years) & $69.06 \pm 7.29$ \\
\hline Height $(\mathrm{cm})$ & $153.21 \pm 9.25$ \\
\hline Weight (kg) & $57.72 \pm 10.69$ \\
\hline $\mathrm{BMI}$ & $24.53 \pm 4.60$ \\
\hline
\end{tabular}

$\mathrm{cm}=$ centimeter, $\mathrm{kg}=$ kilogram, $\mathrm{BMl}=$ body mass index, S.D.=standard deviation

\section{Factors potentially affected rising from a toilet}

In the second phase, the participants were selected based on operating characteristic curve. There were 18 females and 12 males participating in this phase. There were five factors of interest as previously mentioned.
2.1 Rectus femoris muscle activity

The \% MVC of rectus femoris muscles were significantly different $(p-$ value $<0.05)$ in all levels of seat height. The least \% MVC of the rectus femoris muscle during sit to stand was found at the seat height $120.0 \%$ LLL (Table 3).

\subsection{Gluteus maximus muscle activity}

The \% MVC of gluteus maximus muscles were not significantly different $(p-$ value $>0.05)$ in all seat height levels (Table 3).

\subsection{Pressure distribution under the thighs}

There were no significant differences of pressure distribution under the thighs in all three seat height levels (Table 3).

2.4 Time taken in standing from sitting

Time taken in standing from sitting were significantly different $(p-$ value $<0.05)$ between at seat height $120.0 \%$ LLL and $100.0 \%$ LLL, and between $120.0 \%$ and $110.0 \%$ LLL. The least time taken in standing from sitting was found at the seat height $120.0 \%$ LLL (Table 3).

2.5 Satisfaction on standing from sitting

The highest mean score of satisfaction was obtained from the seat height $110.0 \%$ LLL. Older participants were more significantly satisfied when sitting on the toilet seat height $110.0 \%$ LLL than at $120.0 \%$ LLL (Table 3).

Table 2 Anthropometric data

\begin{tabular}{lllll}
\hline \multirow{2}{*}{ Anthropometric $(\mathbf{c m})$} & Sex & \multicolumn{3}{c}{ Percentiles } \\
\cline { 3 - 4 } & & $5^{\text {th }}$ & $5^{\text {th }}$ & $\mathbf{9 5}^{\text {th }}$ \\
\hline \multirow{2}{*}{ Hip breadth } & Male & 29.50 & 33.53 & 38.00 \\
\multirow{2}{*}{ Lower leg length } & Female & 28.50 & 33.35 & 38.00 \\
& Male & 36.65 & 39.33 & 42.67 \\
Buttock to popliteal length & Female & 34.48 & 37.15 & 40.02 \\
& Male & 38.75 & 42.08 & 46.72 \\
\hline
\end{tabular}

$\mathrm{cm}=$ centimeter 


\section{Suitable toilet seat height}

In the second phase, the five factors of interest were ranked by the specialists. The first to third level were (1) the satisfaction, (2) rectus femoris muscle, and (3) the time taken in standing from sitting. At this stage, the data of these three potential factors of the three toilet seat height levels were determined in order to justify a suitable toilet seat height. As the priority of each factor was different, the AHP was applied to determine a suitable toilet seat height for older people. The consistency index and the consistency ratio of this analysis by a hierarchy process were 3.01 and 0.02 , respectively. In this case, a toilet seat height of $110.0 \%$ LLL is the most suitable level with the highest score of AHP. This toilet seat height also represented the $95^{\text {th }}$ percentile of older men and women's LLL (Table 4 and 5).

Table 3 Rectus femoris activity, gluteus maximus activity, pressure distribution under the thighs, time taken from sitting to standing, and satisfaction in different toilet seat height levels

\begin{tabular}{|c|c|c|c|c|}
\hline \multirow{2}{*}{ Variables } & \multicolumn{3}{|c|}{ Mean (S.D.) } & \multirow{2}{*}{$\begin{array}{l}\mathrm{p} \text {-value } \\
\text { among three toilet seat } \\
\text { height levels }\end{array}$} \\
\hline & $100.0 \% \mathrm{LLL}$ & $110.0 \% \mathrm{LLL}$ & $120.0 \%$ LLL & \\
\hline Rectus femoris activity (\%MVC, $\mu \mathrm{v})$ & $51.30(28.60)$ & $45.05(27.35)$ & $39.32(23.08)$ & $<0.001^{\star a, b, c}$ \\
\hline Gluteus maximus activity (\%MVC, $\mu \mathrm{v})$ & $30.66(19.17)$ & $31.47(19.37)$ & $30.15(19.55)$ & 0.073 \\
\hline Pressure distribution under the thighs $(\mathrm{mmHg})$ & $104.56(16.23)$ & $107.71(19.05)$ & $105.43(17.25)$ & 0.162 \\
\hline Time taken from sitting to standing (sec) & $1.43(0.39)$ & $1.56(0.59)$ & $1.30(0.34)$ & $0.007^{\star \mathrm{b}, \mathrm{c}}$ \\
\hline Satisfaction level (ranking score) & $2.10(0.89)$ & $2.27(0.69)$ & $1.63(0.77)$ & $0.039^{* b}$ \\
\hline
\end{tabular}

$\mathrm{LLL}=$ lower leg length, MVC=maximum voluntary contraction, $\mu \mathrm{V}=$ microvolts, $\mathrm{mmHg}=$ millimetres of mercury, sec=second, S.D.=standard deviation

*significant difference in the three toilet seat height levels ( $p-v a l u e<0.05)$

asignificant difference between 100.0\% LLL and 110.0\% LLL (p-value<0.05)

${ }^{b}$ significant difference between 110.0\% LLL and 120.0\% LLL (p-value<0.05)

'significant difference between 120.0\% LLL and 100.0\% LLL ( $p$-value<0.05)

Table 4 Priority and ranking score to determine the suitable toilet seat height evaluated by the Analytic Hierarchy Process

\begin{tabular}{|c|c|c|c|c|c|}
\hline \multirow[b]{2}{*}{ Toilet seat height level } & \multicolumn{3}{|c|}{ Weight score } & \multirow[b]{2}{*}{$\begin{array}{l}\text { Ranking } \\
\text { score }\end{array}$} & \multirow[b]{2}{*}{ Priority } \\
\hline & $\begin{array}{l}\text { Satisfaction } \\
\text { level } \\
(0.54)\end{array}$ & $\begin{array}{l}\text { Rectus femoris } \\
\text { activity } \\
(0.30)\end{array}$ & $\begin{array}{l}\text { Time taken } \\
\text { from sitting } \\
\text { to standing } \\
(0.16)\end{array}$ & & \\
\hline $100.0 \%$ LLL & \multicolumn{3}{|c|}{$(0.30)^{\star}(0.54)+(0.16)^{\star}(0.30)+(0.30)^{\star}(0.16)$} & 0.26 & $3^{\text {rd }}$ \\
\hline $110.0 \%$ LLL & \multicolumn{3}{|c|}{$(0.54)^{\star}(0.54)+(0.30)^{\star}(0.30)+(0.16)^{\star}(0.16)$} & 0.41 & $1^{\text {st }}$ \\
\hline $120.0 \%$ LLL & \multicolumn{3}{|c|}{$(0.16)^{\star}(0.54)+(0.54)^{*}(0.30)+(0.54)^{\star}(0.16)$} & 0.33 & $2^{\text {nd }}$ \\
\hline
\end{tabular}

LLL=lower leg length 
Table 5 The suitable toilet seat height for older people presenting by the percentile

\begin{tabular}{llll}
\hline Sex & $\begin{array}{l}\text { Average } \\
\text { LLL }(\mathbf{c m})\end{array}$ & $\begin{array}{l}110.0 \% \\
\text { LLL }(\mathbf{c m})\end{array}$ & $\begin{array}{l}95^{\text {th }} \text { percentile } \\
\text { of LLL }(\mathbf{c m})\end{array}$ \\
\hline Female & 37.20 & 40.92 & 40.02 \\
Male & 39.34 & 43.27 & 42.67 \\
\hline
\end{tabular}

$L L L=l o w e r$ leg length, $\mathrm{cm}=$ centimeter

\section{Discussion}

The results of this study addressed factors affecting rising from a toilet in older people. It was found that quadriceps femoris muscle activity, particularly the rectus femoris, was altered by a seat height of $100.0 \%, 110.0 \%$, and $120.0 \%$ LLL. In accordance with previous studies, quadriceps muscles are the most active muscles in this task. ${ }^{3,4,37}$ The least \% MVC of the rectus femoris muscles at a toilet seat height of $120.0 \%$ LLL implied a more appropriate seat height for older people to stand easily from the sitting position than the other seat height levels. The optimal performance of quadriceps muscles could lead to good balance control when rising and decrease the risk to fall in older people. ${ }^{14-16}$ The seat height $100.0-120.0 \%$ of LLL has been considered optimal for performing sit to stand in older people. ${ }^{19}$ Appropriate seat height could minimize the degree of knee extension while rising. ${ }^{20,21}$ The finding of the current study is in line with the previous reports in which quadriceps femoris worked efficiently in standing from the seat height of 100.0-120.0\% LLL. ${ }^{18,19}$

Gluteus maximus muscle activity was, however, not affected by all the three toilet seat height levels. The activities of various muscles are apparent while rising from sitting, such as the hamstrings, gluteus maximus and quadriceps femoris. ${ }^{3,38}$ Rising from a high seat height would minimize the degree of hip extensor muscle activity, ${ }^{21}$ while rising from a low seat would increase the degree of hip extensor muscle activity. ${ }^{2,3}$ However, in the current study, rising from a toilet seat height level of 100.0, 110.0 and $120.0 \%$ LLL did not significantly alter the muscle activity of the gluteus maximus muscles.

Pressure distribution under the thighs was also not affected by all three seat height levels. Nevertheless, the lowest pressure distribution under the thighs was found at the toilet seat height of $100.0 \%$ LLL. In spite of no significant difference, this finding is in accordance with the recommendation for a seat height of $100.0 \%$ LLL in order to reduce pressure under the thighs. ${ }^{10,11}$ At the toilet seat height of $100.0 \%$ LLL, participants could fully place their feet on the floor and their body weights were distributed from buttocks to the floor. On the other hand, with the other seat heights the participants could partially place their feet on the floor. However, it was likely that the pressure distribution at $120.0 \%$ LLL was less than at $110.0 \%$ LLL. This might be due to unbalance on their thighs in sitting in some participants. As a result, there were no great differences among the three toilet seat height levels.

The time taken while rising from the toilet was affected by different toilet seat height levels. The time taken in standing from the seat height of $120.0 \%$ LLL was the lowest as compared with the other two seat height levels. A high seat could minimize the degree of motion for both knee extension and hip extension while rising. ${ }^{21}$ Therefore, older individuals could stand more easily and rapidly. The time taken for $100.0 \%$ LLL was less than that for $110.0 \%$ LLL without significant difference could be due to a delay in rising in some participants. The time taken in standing is a behavioral characteristic. ${ }^{30}$ Physical disabilities, such as decreased range of joint motion or muscle weakness, could affect sit-to-stand performance. ${ }^{1,4}$ However, no participant in the current study had any such disability. Therefore, the difference in the time taken to stand from sitting was purely due to the different toilet seat heights. Time taken from sitting to standing has been 
used to indicate performance of knee extensors and hip extensors in an older population. ${ }^{14,15}$ Less time spent in standing from sitting implied better hip and knee extensor muscle performance. ${ }^{15} \mathrm{~A}$ toilet seat height of $120.0 \%$ LLL, as determined by the time taken in standing from sitting, was also supported by the least rectus femoris muscle activity.

The highest satisfaction of older adults on rising from the toilet was found at a seat height of $110.0 \%$ LLL. At this toilet seat height, the individual's entire feet may not be placed on the floor like at the seat height $100.0 \%$ LLL. Higher seat heights made it easier to rise from sitting while too high a seat made older adults feel unsafe. ${ }^{3}$ Ease and safety were related to the level of satisfaction. ${ }^{1}$

The satisfaction of older people was considered as the first priority factor as judged by the specialists in the current study. Satisfaction is a psychological aspect in the contemporary human factor and ergonomic discipline. ${ }^{39}$ The psychological methods utilized the integration of various information that included signals elicited from muscles and joints, and perceptions and experiences of the central nervous system. ${ }^{40}$ The muscle activity of rectus femoris and the time taken while rising from a toilet are considered biomechanical aspects. ${ }^{40}$ Devices designed for older adults, based on ergonomic principles, need to be physically comfortable and acceptable, or at least avoid pain or discomfort. ${ }^{1}$

Previous studies evaluated the suitability of seat height for older people with subjective methods. ${ }^{22}$ This study evaluated toilet seat height suitability based on both objective and subjective methods. The objective methods were the measurement of muscle activity using the EMG and pressure distribution under the thighs using a stabilizer pressure bio-feedback. The subjective measurement was the satisfaction assessment of older participants via the questionnaire. The suitable toilet seat height for older people was $110.0 \%$ LLL indicated by the
AHP. This level is equivalent to the 95th percentile of men and women's LLL. The percentile 95th of anthropometric data is considered to be suitable for most people based on ergonomic principles. ${ }^{10,30}$ As this study was based on the anthropometry data of Thai older people, this suitable level may not be applicable for older people who are much taller or shorter as well as extreme BMI.

\section{Conclusion}

The essential factors affecting rising from a toilet in older adults were satisfaction, the muscle performance of rectus femoris, and the time taken while rising from a toilet. The suitable toilet seat height for older people was $110.0 \%$ LLL or the $95^{\text {th }}$ percentile of older men and women's LLL. This finding could be applied to the design of a proper toilet, taking into account seat height.

\section{Acknowledgement}

The equipment used in this study was supported by the Department of Physical Therapy, Thammasat University. The authors are grateful to all the paticipants and specialists. Appreciation is also expressed to Professor Pongsak Rattanachaikunsopon for proof reading this manuscript.

\section{Funding sources}

This study was funded by: the Faculty of Engineering, Thammasat University.

\section{Conflict of interest}

There is no conflict of interest to report in the current study.

\section{References}

1. Kroemer K, Kroemer H, Kroemer Elbert K. Ergonomics: how to design for ease and efficiency. $2^{\text {nd }}$ ed. Prentice Hall: Pearson; 2001. 
2. Brown CJ, Peel C. Rehabilitation. In: Halter JB, Ouslander JG, Tinetti ME, Studentski S, High KP, Asthana S, editors. Hazzard's geriatric medicine and gernotology [monograph on the Internet]. New York: McGraw-Hill; 2009 [cited 2015 Jul 6]: Available from: http://accessmedicine.mhmedical. com/content. aspx?bookid=371\&Sectionid $=41587636$

3. Green DP, Roberts SL. Kinesiology movement in the context of activity. Missouri: Mosby; 1999.

4. Janet HC, Roberta BS. Neurological rehabilitation: optimizing motor performance. Woburn: Plant A Tree; 2000.

5. Kane RL, Ouslander JG, Abrass IB, Resnick B. Essentials of clinical geriatrics [monograph on the Internet] China: McGraw-Hill Education LLC; 2013 [cited 2015 Jul 13]. Available from: http://accessmedicine.mhmedical.com/content. aspx?bookid $=678 \&$ Sectionid $=44833887$

6. Devito C. Fall injures among the elderly. Community-based surveillance. J Am Geriatr Soc 1988;18:2663-8.

7. Roque MV, Bouras EP. Epidemiology and management of chronic constipation in elderly patients. Clin Interv Aging 2015; 10:919-30.

8. Mourey F, Pozzo T, Rouhier-Marcier I, Didier JP. A kinematic comparison between elderly and youg subjects standing up from and sitting down in a chair. Age Ageing 1998;9:137-46.

9. Harari D. Constipation. In: Halter JB, Ouslander JG, Tinetti ME, Studentski S, High KP, Asthana S, editors. Hazzard's geriatric medicine and gerontology [monograph on the Internet]. New York: McGraw-Hill; 2009 [cited 2015 Jul 12]: Available from: http://accessmedicine.mhmedical.com/content.aspx? bookid $=371 \&$ Sectionid $=41587711$

10. Chan AHS. Preliminary design of an ergonomic self-rise armchair for hong kong elderly. Proceeding of the fifth southeast asian ergonomics society conference on human factor vision-care for the future; November 6-8, 1997; Kuala Lumpur, Malaysia. Kuala Lumpur: Universiti Malaysia Sarawak; 1997.

11. Galumbeck MH, Buschbacher RM, Wilder RP, Winters KL, Hudson MA, Edlich RF. The sit \& stand chair. A revolutionary advance in adaptive seating systems. J Long Term Eff Med Implants 2004;14:535-43.

12. Alexander NB, Grunawalt JC, Carlos S, Augustine J. Bed mobility task performance in older adults. JRRD 2000;37: 633-8.

13. Hughes MA, Myers BS, Schenkman ML. The role of strength in rising from a chair in the functionally impaired elderly. J Biomech 1996;29:1509-13.

14. Ng SSM, Kwong PWH, Chau MSP, Luk ICY, Wan SS, Fong SSM. Effect of arm position and foot placement on the five times sit-to-stand test completion times of female adults older than 50 years of age. J Phys Ther Sci 2015;27:1755-95.

15. Whitney SL, Wrisley DM, Marchetti GF, Gee MA, Redfern MS, Furman JM. Clinical measurement of sit-to-stand performance in people with balance disorders: validity of data for the five-times-sit-to-stand test. Phys Ther 2005;85:1034-45.

16. Meretta BM, Whitney SL, Marchetti GF, Sparto PJ, Muirhead RJ. The five times sit to stand test: responsiveness to change and concurrent validity in adults undergoing vestibular rehabilitation. J Vestibul Res-Equil 2006;16:233-43.

17. Tiedemann A, Shimada H, Sherrington C, Murray S, Lord S. The comparative ability of eight functional mobility tests for predicting falls in community-dwelling older people. Age Ageing 2008;37:430-56.

18. Teo TWL, Mong Y, Ng SSM. The repetitive Five-Times-Sit-ToStand test: its reliability in older adults. Int $\mathrm{J}$ Ther Rehabil 2013;20:122-30.

19. Kuo YL. The influence of chair seat height on the performance of community-dwelling older adults' 30-second chair stand test. Aging Clin Exp Res 2013;25:305-9.

20. Kernozek WT. Biomechanical aspects of the sit to stand and stand to sit during toilet seat use: effects of age and seat height on kinematic and kinetic factor. Minnesota: University of Minnesota; 1994

21. Hurley ST, Rutherford DJ, Hubley-Kozey C. The effect of age and seat height on sit-to-stand transfer biomechanics and muscle activation. Phys Occup Ther Geriatr 2016;34:169-85.

22. Capezuti E, Wagner L, Brush BL, Boltz M, Renz S, Secic M. Bed and toilet hight as potential enviromental risk factor. Clin Nurs Res 2008;17:50-66.

23. Alexander NB, Koester DJ, Grunawalt JA. Chair design affects how older adults rise form a chair. J Am Geriatr Soc 1996;44: 356-62.

24. Yamada T, Demura S. Influence of the relative difference in chair seat height according to different lower thigh length on floor reaction force and lower-limb strength during sit-tostand movement. J Physiol Anthropol Appl Hum Sci 2004;23: 197-203.

25. Zemp R, Taylor WR, Lorenzetti S. Are pressure measurements 
effective in the assessment of office chair comfort/discomfort? A review. Appl Ergon 2015;48:273-82.

26. International standard. ISO 7250-1 Basic human body measurements for technological design part 1: body measurement definitions and landmarks. Geneva: International Organization for Standardization; 2008.

27. National Statistical Office Thailand. The population and housing census 2013 [monograph on the Internet]. Bangkok: The Office; 2013 [cited 2015 Jul 22]. Available from: http:// popcensus.nso.go.th/report/WholeKingdom_T.pdf

28. Jarutat T, Ketpichayawattana C, Lohmaneenoppara S, Chalaphati K. The minimum standard study program for housing and the environment of the elderly: complete research report. Bangkok: Office of Research Fund National Health Foundation and the Office of Health Promotion Foundation; 2005.

29. Yamane T. Statistics: an introductory analysis. $3^{\text {rd }}$ ed. New York: Harper and Row; 1973.

30. Sanders MS, McCormick EJ. Human factors in engineering and design. $7^{\text {th }}$ ed. New York: McGraw-Hill; 1993.

31. McLelland I, Joan S. The ergonomics of toilet seats. Human Factors 1982;24:713-25.

32. Afifi M, Al-Hussein M, Bouferguene A. Technology applied to geriatric medicine: geriatric bathroom design to minimize risk of falling for older adults-a systematic review. Eur Geriatr Med 2015.

33. Konrad P. The ABC of EMGA Practical Introduction to Kinesio- logical Electromyography 2006 [monograph on the Internet]. Arizona: Noroxon U.S.A.; 2005 [cited 2016 May 13]. Available from: http://www.noraxon.com/wp-content/uploads/2014/ 12/ABC-EMG-ISBN.pdf

34. The European Recommendations for Surface ElectroMyo Graphy. The SENIAM project (Surface EMG for Non-Invasive Assessment of Muscles) [monograph on the Internet]. Enschede: Roessingh Research and Development; 2006 [cited 2016 May 13]. Available from: from http://www.seniam. org

35. Pilot DF, Beck CT. Nursing Reseach: generating and assign evidence for nursing practice. $8^{\text {th }}$ ed. Philadelphia: Lippincott; 2008.

36. Titichattawong R. Prioritizing key importance factor for machine selection by analytic hierarchy process: a case study of jewelry factory. Pathum Thani: Rajamangala University of Technology Thanyaburi; 2014.

37. Schecnkman M, Berger AR, Riley OP, Mann WR, Hodge WA. Whole-body movements during rising to standing form sitting. Phys Ther 1990;70:10.

38. Huston LR. Fundamentals of biomechanics. Florida: Taylor \& Francis Group; 2013.

39. EIAC. Ergonomics Abstracts, Ergonomics Information, Analysis Centre SoMaME. Birmingham: University of Birmingham; 2000.

40. Amit B, James DM. Occupational ergonomics: theory and applications. New York: Marcel Dekker; 1996. 